\title{
A TIMELY INTERACTIVE RECOMMENDER SYSTEM FOR A WOMEN-AND-CHILDREN E-COMMERCE PLATFORM
}

\author{
Chang-Ming Yan \\ Ming Chuan University \\ 5 De Ming Rd., Gui Shan District, Taoyuan County 333, Taiwan \\ samyan@mail.mcu.edu.tw \\ Sheng-Hui Chiu \\ Ming Chuan University \\ 5 De Ming Rd., Gui Shan District, Taoyuan County 333, Taiwan \\ jammy1@gmail.com \\ Wen-Lung Shiau \\ Ming Chuan University \\ 5 De Ming Rd., Gui Shan District, Taoyuan County 333, Taiwan \\ mac@mail.mcu.edu.tw
}

\begin{abstract}
E-commerce (EC) has grown rapidly and the recent marketing of women and children $(\mathrm{W} \& \mathrm{C})$ products has gained much attention. One survey shows $\mathrm{W} \& \mathrm{C}$ product sales online have doubled compared to an only $10 \%$ increase in stores. Given that W\&C products characteristically have a variety of product categories and are suitable for a relatively short period of time, consumers may not have enough product knowledge to purchase appropriate products. This research proposes a timely interactive recommendation mechanism to be applied to an EC W\&C product based on "age of child" as a time factor, the generation of a suitable time interval to filter the categories, and a dynamic display of categories and products. An interactive critique-based recommendation mechanism is thereby designed to help consumers identify their modified requests that reflect current dissatisfaction with a product. Through this process users can acquire product knowledge and purchase the most suitable product. An experiment based on the proposed mechanism is performed. The results demonstrate that the participants were significantly more satisfied with the proposed timely interactive recommender system than the general e-commerce, in terms of the factors of information content, personalized services, user interface, system value, and perceived system diagnosticity.
\end{abstract}


Keywords: Recommender System, Knowledge-Based Recommender System, Critique-Based Recommender System, E-Commerce, Women and Children Product EC

\section{INTRODUCTION}

With the maturation of Internet technology, e-commerce (EC) has grown rapidly with millions of EC sites in operation worldwide. The question remains, however, how does one provide consumers with suitable products and maintain user loyalty. One of most indispensable methods for dealing with these issues is the recommender system (RS). As an example, by employing a RS, Amazon.com overcame the crisis created by the bursting of the Internet bubble in 2000, and grew rapidly to become the largest EC site globally. Currently, a RS has become one of the key factors for successful EC sites.

The RS is an information system that can provide suitable products to meet the needs of a user. Its main task is to filter products effectively, and also to identify user preferences to provide them with appropriate products ${ }^{1}$, 2,3 . For this reason, an RS can help EC sales in many ways, such as by converting browsers into buyers, increasing cross-selling, and building loyalty ${ }^{4}$.

Electronic-commerce sites for the women and children (W\&C) products are growing quickly, especially during the recent recession period. There is a saying in the marketing field, during a recession, the last budget item to be cut by consumers are items for children, followed by the mother, then the pet, with the father being considered first. Moreover, the recession has changed consumer purchasing behavior as well, with increasing numbers of consumers preferring online shopping rather than store shopping. According to one survey, W\&C products sales doubled compared to an increase of only $10 \%$ for stores, and more than half of parents purchase $\mathrm{W} \& \mathrm{C}$ products online ${ }^{5}$. This increasing demand has resulted in more $\mathrm{W} \& \mathrm{C}$ products categories and even specialty EC sites. A look at these sites, however, reveals that besides being a specific site for $\mathrm{W} \& \mathrm{C}$ products, these W\&C EC sites are not much different in comparison to general EC sites. Very few functions have been designed for the characteristics of W\&C products, which include a variety of product categories, suitability that is limited to a certain time period, and a consumer that may have little knowledge of the products. 
Therefore, the aim of this research is:

1. To apply to and integrate with W\&C EC the factor of "age of child" to automatically filter out unsuitable products, with the capacity to handle multiple-children situations.

2. To design a recommendation presentation that can adjust dynamically in order to provide suitable categories and products for users.

3. To help users learn relevant knowledge during the purchase process.

\section{LITERATURE REVIEW}

\subsection{Electronic Commerce}

Electronic commerce (EC) can be described as the process of buying, selling, transferring or exchanging products, services, and/or information via computer networks, including the Internet $^{6}$. This totally changes the mechanism of traditional commerce. This creates many new business models and opportunities ${ }^{7}$, and also impacts the purchase behavior of consumers.

EC can be classified into different categories. According to the frequency of purchase, there can be the class of frequent vs. infrequent purchasing activity ${ }^{8}$. Frequently purchased activities focus on eliciting customer preferences and suggesting products in line with the customer profile. Infrequently purchased items are likely to have less defined objectives and preferences, and as such, their tasks will tend to be ill structured. Moreover, depending on the product type, there is the class of durable items and consumable items. Durable items normally have a higher price, and the purchase behavior is more related to user preferences.

\subsection{Recommender Systems}

A recommender system (RS) can be described as an information system to provide product information that is interesting to users and based on users' preferences $^{1,9}$. Besides information filtering, its main task is focused on finding the preferences of the user, and thus provides the item that the user would be interested in ${ }^{1,2}$. Importantly, with the support of the RS, information overload and search complexity can be reduce ${ }^{10}$. Moreover, the relationship between users and venders can be strengthened, the service quality enhanced, and as a result, profits increased. Therefore, an RS can increase sales, and also better manage customer relationships that lead to higher loyalty and increased competitive barriers ${ }^{10}$.

An RS can be classified in terms of information filtering approaches that include content-based, collaborative filtering, demographics-based, and knowledge-based RS. The content-based (CB) and collaboration filtering 
(CF) recommendation methods are the most famous and frequently applied methods. Further, the combination of both is called the hybrid recommendation method ${ }^{3,4,11,12,13}$, which has recently drawn the attention of many researchers. In $\mathrm{CB}$ recommendation, the main task is to analyze item features and compare them with a user's past purchase history, behavior, interests, or ratings for items ${ }^{12}$. A relationship between item features and user characteristics is then established. Through an understanding of similarities in this relationship, the RS can recommend users items that they may like or be interested in. CF recommendation matches users with similar interests and ratings ${ }^{12}$. It collects a user's past purchase history and analyzes these data to establish a personalized user profile, and then combines them into groups of similar users. The fundamental assumption of CF is that if users rate items similarly, or have similar behaviors (e.g., buying, watching, listening), they will similarly rate or act as such on other items. In this way, the items purchased by one user can be recommended to others who are in the same group and have not yet purchased this item ${ }^{4,14}$.

In several situations, however, $\mathrm{CB}$ and $\mathrm{CF}$ methods may not be the best option. The first typically involves infrequently purchased products, such as cars. Systems may not be able to obtain much user rating information ${ }^{15}$. Another situation is when timing is an important factor. Historical preferences from five months ago might not be inappropriate for parents with a six-month old baby.

\subsection{Knowledge-Based Recommendation}

Knowledge-based recommender systems (KB RS) can help tackle the aforementioned challenges, because there is no rating information needed in advance for the derived recommendation. The KB RS is defined as a system that "guides a user in a personalized way to interesting or useful objects in a large space of possible options or that produces such objects as output"15. Two basic types of knowledge-based recommender systems are constraint-based and case-based systems ${ }^{3,15}$. These recommendations differ in the way they use the provided knowledge. Whereas case-based recommendations focus on the retrieval of similar items and use similarity metrics to retrieve items that are similar to the specified customer requirements, constraint-based recommendations rely on an explicitly defined set of recommendation rules.

Earlier versions of case-based recommendations followed a pure query-based approach, in which users had to specify their requirements until a target item had been identified. The drawback of pure query-based approaches is that it cannot satisfy users, who may not know what they are seeking, by helping them navigate the item space to find useful alternatives. 
Critiquing is an effective way to support such navigations and it is one of the key concepts of case-based recommendation. The concept of critiquing is that the users identify their modified requests that are not currently satisfied with an item ${ }^{15,16}$. Ricci and Nguyen ${ }^{17}$ applied the critique technology in a mobile recommendation structure.

\subsection{Women and Children Products}

The RS has been applied in many different fields, with EC being one of the most prolific users as it can help the consumers' purchasing process. Given that for recommendations timing is an important factor, the present RS considers "time" as two broad types:

1. Since user preferences may operate in terms of a length of effectiveness, they can be classified as either long-term preferences or short-term-preferences. These RSs with long-term preferences describe preferences that do not change with time, and can thus be considered as time-independent preferences. In contrast, short-term preferences may change frequently, with some changing with every browsing action, such as for News RSs. For this kind of RS, the "time" factor becomes crucial.

2. Regarding targeted entities, "time" may relate to either products or users. For the product, it can be applied as an expiry date or a time period of availability. And for the users, time may relate to the career of the user, with different career stages possibly having different requirements. For the user's career stage, one of the most challenging periods of time is the first few years of having a new baby (including pregnancy).

As new parents, many users entering this period may not have enough knowledge to know what to purchase. In reality, these new parents need various different women and children (W\&C) products at different stages. However, these $\mathrm{W} \& \mathrm{C}$ products include the characteristics of many different categories of products, such as foods, clothes, transportation, and toys. And during different time periods, i.e., related to the child's age, there are different product requirements, often associated with time periods that may be short, sometimes lasting only a few months. Since the users may not have enough domain knowledge about different categories of W\&C products, they may be incapable of expressing their preferences about products clearly, and as a result experience difficulties and frustrations with purchasing.

According to one survey more than half of the parents purchase W\&C products online, which ranks third after baby stores and pharmacies ${ }^{5}$. Nowadays, more and more W\&C specific websites are being built for this specific market. However, according to our investigation, very few of them 
apply the factor of "time" in the supporting process for recommendations. In this research, we try to apply the "age of child" as a recommendation factor.

\section{RESEARCH METHOD}

\subsection{System Design}

In order to take into account the characteristics of a $\mathrm{W} \& \mathrm{C}$ product website, a critique-based interactive RS aggregated with a time factor is proposed. The modules of this system are described as bellow.

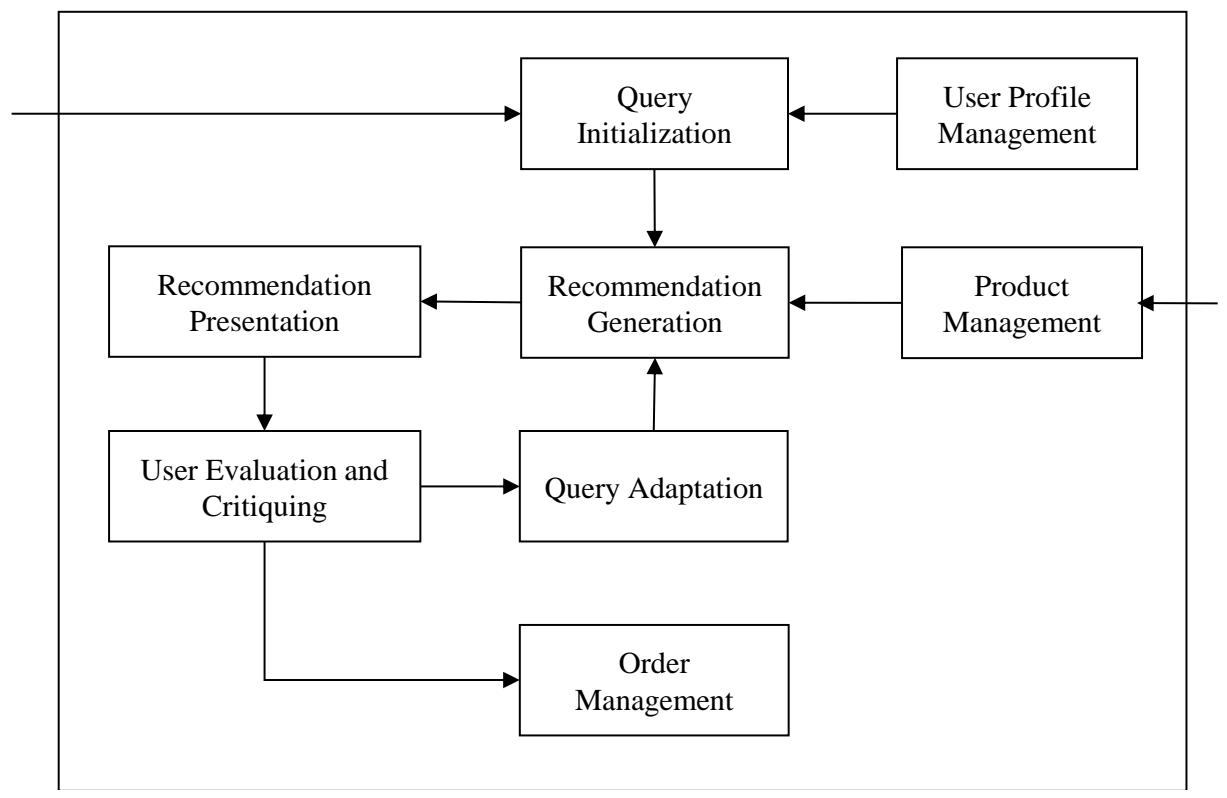

Figure 1. Interactive RS architecture

1. User Profile Management (UPM): The user profile contains three types of information: basic personal information, like user name, birthday, children's birthday; long-term preference; and user interactive history.

2. Query Initialization (QI): This module generates a personalized time-dependent request. It receives the query from the user and integrates the information into the user profile (e.g., child age, long term preference) from the UPM module.

3. Product Management (PM): This module contains the product's information, including product details, product category constraints and critique-able attributes.

4. Recommendation Generation (RG): All the RS methods are implemented in this module. The input of this module can come from the QI for a first time query or from the Query Adaption (QA) during the critiquing cycle, and it may be the personalized query or the 
critiquing query. The functions of this module include filtering out unsuitable products; calculating the similarity of products; and providing recommended candidate products.

5. Recommendation Presentation (RP): This module presents the candidate products to users, which can be organized according to the user's habits.

6. User Evaluation and Critiquing (UE\&C): When the candidate products are presented to users, they can reply with opinions and comments, and if users are not satisfied with the recommended product, they can critique it with an adjusted direction.

7. Query Adaptation (QA): This module accepts the critique comment from the UE\&C and then adjusts the request accordingly.

8. Order Management $(\mathrm{OM})$ : When the user is satisfied with the candidate product, the user then puts the product into the shopping cart; this module manages the process of ordering, and also provides the purchase product to the UPM stored as purchase history data, and then finishes the critique process.

Table 1. User profile with user and child's information

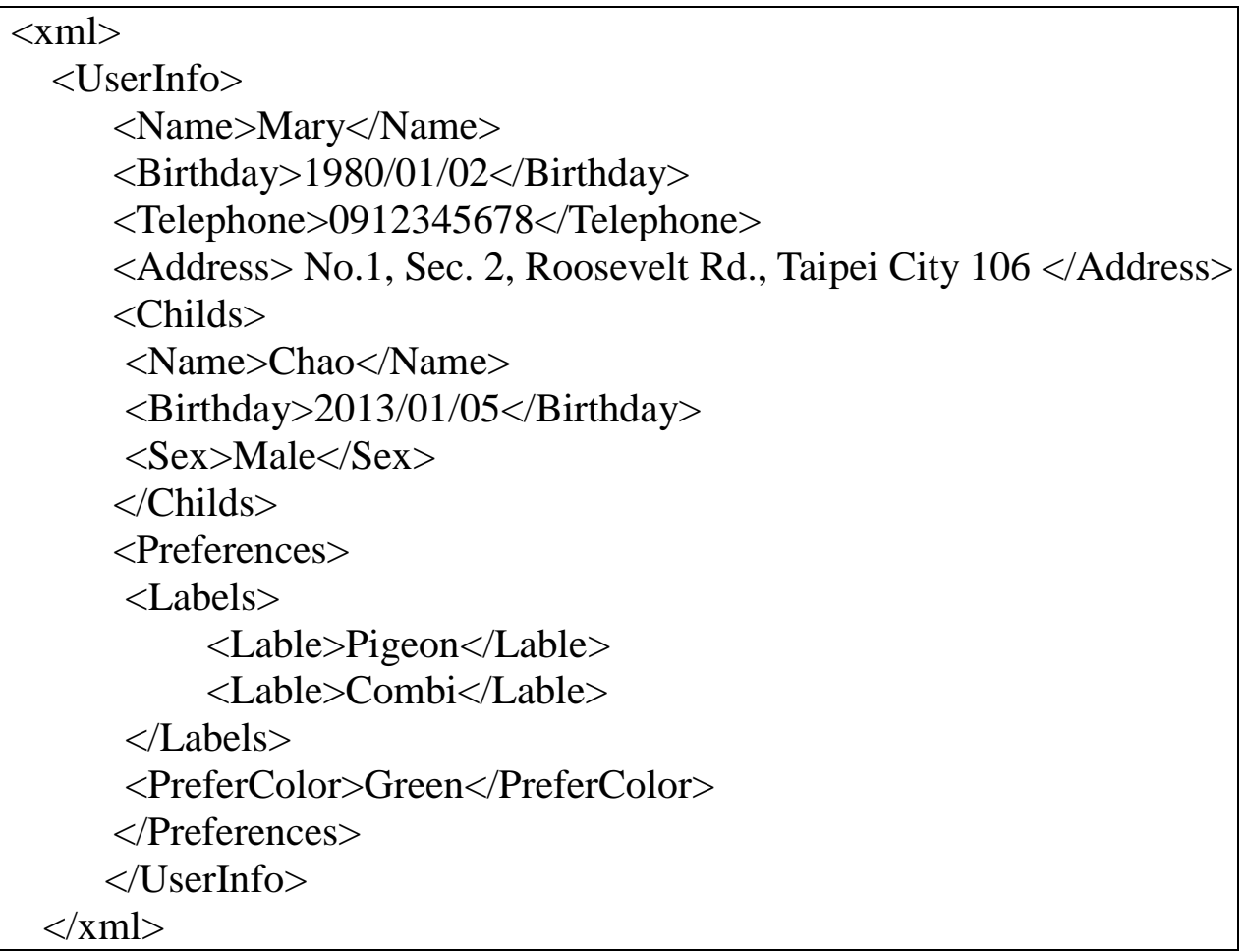




\subsection{User Profile with Timely Factor}

The user profile, which is the core of the RS, in this research contains the user's personal information including the birthday of the child, and is thus able to derive the child's age. Even if there are multiple children in one profile, it can still be represented as containing two values in this age factor. The user profile is described in XML format, and displayed in Table 1.

In this research, it is assumed that the age of child can indicate a user requirement. However, in a real situation, the child's age may not exactly reflect the request. Every child may be a little bit earlier or later than the norm. Therefore, instead of applying the "age" directly, this research uses a time interval to represent the age of child. The distribution deviations $\delta^{-}, \delta^{+}$are introduced to represent the negative and positive deviations of child's real age (Age). Therefore, the time interval for a child's age is described as

$$
\text { [Age } \left.-\delta^{-}, \text {Age }+\delta^{+}\right]=\left[t_{l}^{u}, t_{u}^{u}\right],
$$

where $t_{l}^{u}, t_{u}^{u}$ represent the lower and upper bounds of the user's child age interval in this proposed RS.

Similarly, the time range for product can be described as

$$
\left[t_{l}^{p}, t_{u}^{p}\right]
$$

where $t_{l}^{p}, t_{u}^{p}$ are the lower and upper time bounds of the product.

The relationship between the age of child interval and the time range of product may be presented in a time line, as depicted in Figure 2.

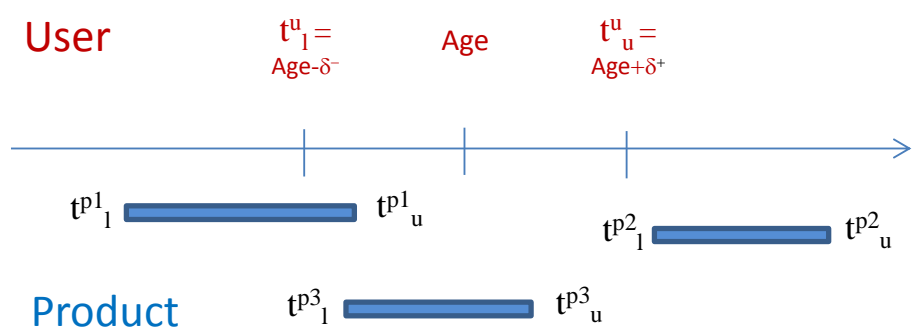

Figure 2. Timeline between the child-age interval and the time range of products

If the following condition exists,

$$
t_{u}^{p}<t_{l}^{u}, \text { or } t_{l}^{p}>t_{u}^{u}
$$


this means the product is not contained in the range of suitable age, and thus the product is filtered out. Otherwise, this product is selected and is displayed in the adaptive recommendation presentation.

Moreover, if the following situation is satisfied,

$$
t_{l}^{p}<\text { Age }<t_{u}^{p}
$$

this means that the product is designed for a child of this age. For this reason, the product should have a higher priority and higher rank.

For example, if a child is aged 14 months (Age =14), the set distribution deviation $\delta^{-}, \delta^{+}=4$ months, then $\left[t_{l}^{u}, t_{u}^{u}\right]=[10,18]$ and the time range of products are $\mathrm{P}_{1}=[6,12], \mathrm{P}_{2}=[20,30], \mathrm{P}_{3}=[12,16]$. As the product $\mathrm{P}_{2}$ satisfies $\mathrm{Eq}(1)$, and is filtered out. Therefore, only the $\mathrm{P}_{1}$ and $\mathrm{P}_{3}$ are displayed. Moreover, as the $\mathrm{P}_{3}=[12,16]$ range contains the Age $=14$, it will therefore have a higher ranking order.

\subsection{Multiple Attribute Interactive Mechanism}

Every product contains many different attributes, but only some of them are of interest to the users. Therefore, these attributes of interest are provided to users to be adjusted interactively as a means to represent users' opinions. These opinions are useful, especially when users do not have enough knowledge about the product to provide their preferences for the attributes.

During the interactive process, the attributes of the candidate product are displayed for the user. The candidate product can be represented as

$$
\mathrm{P}=\left\{\mathrm{v}_{1}, \mathrm{v}_{2}, \ldots, \mathrm{v}_{n}\right\},
$$

$\mathrm{P}$ is the product having the value set of the attribute $\mathrm{v}_{\mathrm{i}}{ }^{7}$.

If users are not satisfied with the certain attribute value, they can indicate this by clicking the upward and downward arrow buttons $(\boldsymbol{\Lambda} \cdot \boldsymbol{\nabla})$ to adjust the value. For the quality attributes, the list of attribute values can be displayed for the selection. For the numerical attributes, the upward and downward button can be represented as a certain percent of adjustment. Given that $\beta_{i}$ is the adjusted value for different attributes, the adjusted attribute value $v_{i}^{\prime}$ is

$$
\mathrm{v}_{\mathrm{i}}^{\prime}=\mathrm{v}_{\mathrm{i}} \pm \beta_{\mathrm{i}}
$$

And the candidate product is generated according to the new adjusted attribute values $v_{i}$ ' in a new cycle. If users are still not satisfied with the value of the attribute, they can indicate that

$$
\mathrm{v}_{\mathrm{i}}^{\prime \prime}=\mathrm{v}_{\mathrm{i}}^{\prime} \pm \beta_{\mathrm{i}}
$$


The system records all of the interactive history. It is assumed that the more user clicks for a certain attribute indicates that the user is more interested in this attribute.

In this research, every product has several attributes for interaction. All the products have the two interactive attributes of price and rating in common, and different categories of product have different attributes. For example, the baby bottle product has adjustable attributes for "material", "heat resistance temperature" and "brand", but for the stroller, the adjustable attributes are "weight" and "brand".

\subsection{Recommendation Process}

The process of this recommendation system for a W\&C EC system is described as follows:

1. When users want to purchase $\mathrm{W} \& \mathrm{C}$ products, they send their request to the QI module, which is combined with the users' long-term preference information obtained from the PM module. If the users are first-time visitors, they are required to provide basic personal information, including a child's birthday. If the users have visited before, their personal information and history information exist in the user profile as their long-term preferences. These types of information will be integrated into the user requirements in the QI module. In this step, the "time", child's age, is the key factor to integrate.

2. After the QI aggregates all this information, the aggregated request is sent to the RG module, and through filtering and comparing with product information, a suitable product category is obtained and displayed for the user in the RP module.

3. When users receive the recommended product list, they may evaluate whether the product satisfies their requirements.

i. If the answer is no, the user can start to critique the product by appointing the product attribute for adjustment. The critique request is sent to the QM module and adjusts the original user request, and is sent to the PM again for a new run of the recommendation critique cycle.

ii. If the user is satisfied with this product, the product will be sent to the shopping cart and the order process will start in the OM module; the product information will then be sent to the UPM module to modify the user profile, where the information can be used in the future when the particular user has a new purchase attention. 


\section{EXPERIMENT AND RESULTS}

A prototype system based on the proposed approach was developed to evaluate its performance. Forty consumers were invited to participate in this experiment. Participant characteristics are shown in Table 2

Table 2. Sample characteristics

\begin{tabular}{|c|c|c|c|}
\hline \multicolumn{2}{|c|}{ Category } & No. of sample & Percentage $\%$ \\
\hline \multirow{2}{*}{ Gender } & Male & 17 & $48.39 \%$ \\
\hline & Female & 23 & $51.61 \%$ \\
\hline \multirow{5}{*}{ Age } & $21-25$ & 2 & $5.00 \%$ \\
\hline & $26-30$ & 7 & $17.50 \%$ \\
\hline & $31-35$ & 12 & $30.00 \%$ \\
\hline & $36-40$ & 16 & $40.00 \%$ \\
\hline & $40-45$ & 3 & $7.50 \%$ \\
\hline \multirow{3}{*}{$\begin{array}{c}\text { Marriage } \\
\text { status }\end{array}$} & Single & 3 & $7.50 \%$ \\
\hline & Married (no kids) & 4 & $10.00 \%$ \\
\hline & Married (has kids) & 33 & $82.50 \%$ \\
\hline \multirow{4}{*}{$\begin{array}{c}\text { No of } \\
\text { children }\end{array}$} & 0 & 7 & $17.50 \%$ \\
\hline & 1 & 19 & $47.50 \%$ \\
\hline & 2 & 12 & $30.00 \%$ \\
\hline & 3 & 2 & $5.00 \%$ \\
\hline \multirow{7}{*}{$\begin{array}{l}\text { Age of } \\
\text { child }\end{array}$} & $7 \sim 12$ months & 4 & $7.84 \%$ \\
\hline & 13 18 months & 12 & $23.53 \%$ \\
\hline & 19 24 months & 9 & $17.64 \%$ \\
\hline & 25 30 months & 1 & $1.96 \%$ \\
\hline & 31 36 months & 3 & $5.88 \%$ \\
\hline & $48 \sim 60$ months & 7 & $13.73 \%$ \\
\hline & $>60$ months & 7 & $13.73 \%$ \\
\hline
\end{tabular}

In order to estimate the relative advantage of the proposed recommendation mechanism, this experiment contains two modes, the proposed timely interactive recommendation (TIRS) mode and the control mode that is an EC mode with all the general EC functions. The general EC mode is identical to the TIRS, but without the recommendation ability. Each participant was asked to identify an expected product and to apply both modes to obtain suitable products. The satisfaction level, developed by Linag $^{1}$ and Jiang and Benbasat ${ }^{18}$, of participants of these two modes are shown in Table 3.

The experiment result indicates the mean of satisfaction level of TIRS in 5 factors, information content, personalized services, user interface, 
system value, and perceived system diagnosticity, and all were greater than the value in general EC. Applying the paired t-test, the results show that the satisfaction levels in TIRS were significantly better than the general EC in all 5 factors.

Table 3. Mean of the satisfaction level of two modes

\begin{tabular}{|c|c|c|c|c|c|}
\hline \multirow{4}{*}{$\begin{array}{l}\text { Information } \\
\text { Content }\end{array}$} & \multirow{4}{*}{$\begin{array}{c}\text { Item } \\
\text { Find item wanted } \\
\text { Filtered out unwanted } \\
\text { Captured the right } \\
\text { category }\end{array}$} & \multicolumn{2}{|c|}{ General EC } & \multicolumn{2}{|c|}{ TIRS } \\
\hline & & 3.85 & \multirow{3}{*}{3.69} & 5.98 & \multirow{3}{*}{5.93} \\
\hline & & 3.58 & & 5.88 & \\
\hline & & 3.65 & & 5.93 & \\
\hline \multirow{3}{*}{$\begin{array}{l}\text { Personalized } \\
\text { Services }\end{array}$} & $\begin{array}{l}\text { Attentive to user } \\
\text { needs }\end{array}$ & 3.35 & \multirow{3}{*}{3.31} & 5.85 & \multirow{3}{*}{5.85} \\
\hline & Captured interests & 3.20 & & 5.78 & \\
\hline & Adaptive service & 3.40 & & 5.93 & \\
\hline \multirow{4}{*}{$\begin{array}{c}\text { User } \\
\text { Interface }\end{array}$} & Easy to use & 3.73 & \multirow{4}{*}{3.71} & 5.98 & \multirow{4}{*}{5.71} \\
\hline & Friendly & 3.45 & & 5.78 & \\
\hline & Properly formatted & 3.8 & & 5.6 & \\
\hline & Clear presentation & 3.88 & & 5.48 & \\
\hline \multirow{2}{*}{ System Value } & Useful & 3.75 & \multirow{2}{*}{3.79} & 5.50 & \multirow{2}{*}{5.50} \\
\hline & Efficient & 3.83 & & 5.50 & \\
\hline \multirow{4}{*}{$\begin{array}{l}\text { Perceived } \\
\text { system } \\
\text { diagnosticity }\end{array}$} & Helpful for evaluation & 3.38 & \multirow{4}{*}{3.47} & 5.95 & \multirow{4}{*}{5.74} \\
\hline & $\begin{array}{l}\text { Helpful in being } \\
\text { familiar }\end{array}$ & 3.43 & & 5.80 & \\
\hline & Helpful in & & & & \\
\hline & $\begin{array}{l}\text { understanding the } \\
\text { performance }\end{array}$ & 3.60 & & 5.48 & \\
\hline
\end{tabular}

Note: A Likert 7-point scale was applied (1: totally disagree, 7: totally agree)

\section{CONCLUSION}

With the maturation of Internet technologies, e-commerce has grown rapidly, and recommender systems are ubiquitously applied in e-commerce as a means to overcome the problem of information overload. Although many specialized women and children (W\&C) product categories or websites have been developed, there are several challenges that still need to be resolved. An important example is that $\mathrm{W} \& \mathrm{C}$ products have various categories like food, clothes, and toys, and most of these apply to children at a specific age period. Further, the requirements of the parent user may change frequently in that the product is time-sensitive and its suitable period-of-use may be short. However, as the product categories and 
requirements change frequently, most of users may not have enough product knowledge to make optimal purchases.

For these reasons, this research proposed a timely interactive RS (TIRS), employing the "age of child" as a time factor that was applied in the RS process to automatically filter out unsuitable items. As not all children will always suit a product time range, an age interval was applied instead of a precise age, to facilitate the sharing of a suitable product range. Moreover, this filtering process can be applied to multiple-children situations. Also, when "age of child" is applied, the candidate products are determined specifically for a particular user and the presentation is adjusted accordingly.

Furthermore, as the parent user may not have enough product knowledge, and as it is difficult to provide precise user preferences, this research proposes one kind of the knowledge-based RS, i.e., a critiqued-based RS, to solve these challenges. A critiqued-based RS helps consumers to identify their modified requests that are not currently satisfied with a product and to gradually reach the suitable product user interest. As such, users are not forced to identify their preference in advance, and the system can also help users to obtain product knowledge and refine user preferences during the interactive process.

A prototype system based on the proposed approach was developed and an experiment was designed to compare the proposed TIRS with the control mode named general EC, which is identical to the TIRS, having all the typical EC functions except for recommendation. From the experiment results it is clear that the participants were significantly more satisfied with the new TIRS architecture in all aspects (factors of information content, personalized services, user interface, system value, and perceived system diagnosticity) compared to the general EC site.

\section{CONTRIBUTIONS}

The contribution of this study to the academic field is the proposal of a mechanism using time interval as filter factor in the development of EC. This can lead to a more precise timely recommendation.

In terms of contributing to the practical field, this research provides a personal $\mathrm{W} \& \mathrm{C}$ product $\mathrm{EC}$ to help $\mathrm{EC}$ venders provide each user with a personal EC tailored to the child's needs and age. And through an interactive critique-based RS mechanism, a user's insufficient product knowledge can be supplemented and enhanced during the interactive process. Further, as users continue using and interacting with the system, it can obtain users' preferences and can provide better product recommendations. This can 
substantially decrease the effort users need to make purchases and increase user satisfaction levels.

\section{REFERENCE}

[1] T.P. Liang, H.J. Lai, and Y.C. Ku, Personalized content recommendation and user satisfaction: Theoretical synthesis and empirical findings. Journal of Management Information Systems, 23(3), p45-70, 2007. http://dx.doi.org/10.2753/MIS0742-1222230303.

[2] P. Resnick, and H.R. Varian, Recommender systems. Communication $\begin{array}{llll}\text { of } & \text { ACM, } & \text { 40(3), } & \end{array}$ http://dx.doi.org/10.1145/245108.245121.

[3] D. Jannach, M. Zanker, A. Felfernig, and G. Friedrich, Recommender systems: An introduction. New York: Cambridge University Press, 2010. http://dx.doi.org/10.1017/CBO9780511763113.

[4] J.B. Schafer, J.A. Konstan, and J. Riedl, E-commerce recommendation applications. Data Mining and Knowledge Discovery, 5(1/2), p115-153, 2001. http://dx.doi.org/10.1007/978-1-4615-1627-9_6.

[5] China Times, 宅媽味血抙 網購業績倍增. Retrieved on September 1, 2013

form http://money.chinatimes.com/newmoney/stat/HotNews_Content.aspx?s id=299846

[6] E. Turban, and D. King, Electronic commerce 2012: Managerial and social networks perspectives. U.S.A.: Prentice Hall, 2011.

[7] R. Vahidov, and F. Ji, A diversity-based method for infrequent purchase decision support in e-commerce. Electronic Commerce Research and Applications, 4(2), p143-158, 2005. http://dx.doi.org/10.1016/j.elerap.2004.09.001.

[8] W.P. Lee, C.H. Liu, and C.C. Lu, Intelligent agent-based systems for personalized recommendations in e-commerce. Expert Systems with Applications, 22(4), p275-284, 2002. http://dx.doi.org/10.1016/S0957-4174(02)00015-5.

[9] C.-P. Wei, M.J. Shaw, and R.F. Easley, A survey of recommendation systems in electronic commerce. In R.T. Rust and P.K. Kannan (Eds.), E-service: New direction in theory and practice (p168-199). New York: M. E. Sharpe, Inc. 2002.

[10] B. Xiao, and L. Benbasat, E-commerce product recommendation agents: use, characteristics, and impact. MIS Quarterly, 31(1), p137-209, 2007.

[11] E.A. Stohr, and S. Viswanathan, Recommendation Systems: Decision Support for the Information Economy. In K.E. Kendall (Ed.), Emerging information technologies (p21-44). Thousands Oaks, Califorlia: $\quad$ SAGA $\quad$ publications 1999. 
http://dx.doi.org/10.4135/9781483345505.n2.

[12] M. Montaner, B. Lopez, and J.L.D.L. Rosa, A taxonomy of recommender agents on the internet. Artif. Intell. Rev., 19(4), p285-330, 2003. http://dx.doi.org/10.1023/A:1022850703159.

[13] F. Ricci, L. Rokach, B. Shapira, and P.B. Kantor, Recommender systems handbook. New York: Springer, 2011. http://dx.doi.org/10.1007/978-0-387-85820-3.

[14] J.A. Konstan, B. Miller, D. Maltz, J. Herlocker, L. Gordon, and J. Riedl, GroupLens: Applying collaborative filtering to usenet news. Communications of the ACM, 40(3), p77-87, 1997. http://dx.doi.org/10.1145/245108.245126.

[15] R. Burke, Knowledge-based recommender systems. In A. Kent (Ed.), Encyclopedia of library and information systems (p175-186). New York: Marcel Dekker Inc., 2000.

[16] L. Chen, and P. Pu, Critiquing-based recommenders: Survey and emerging trends. User Modeling and User-Adapted Interaction, 22(1-2), p125-150, 2012. http://dx.doi.org/10.1007/s11257-011-9108-6.

[17] F. Ricci, and Q.N. Nguyen, acquiring and revising preference in a critique-based mobile recommender system. IEEE intelligent systems, 22(3), p22-29, 2007. http://dx.doi.org/10.1109/MIS.2007.43.

[18] Z. Jiang, and I. Benbasat, The effects of presentation formats and task complexity on online consumers'product understanding. MIS Quarterly, 31(3), p475-500, 2007. 
